\title{
Efficacy of district tuberculosis co-ordinating team on health service performance for suspected TB patient in district hospital
}

\author{
Sasithorn Tangsawad \\ Department of Disease Control, Ministry of Public Health, Khon Kaen, \\ Thailand, and \\ Surasak Taneepanichskul \\ College of Public Health Sciences, Chulalongkorn University, Bangkok, Thailand
}

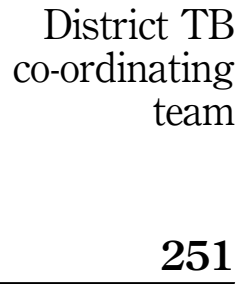

Received 27 October 2017 Accepted 29 January 2018

\begin{abstract}
Purpose - The purpose of this paper is to study the efficacy of a district tuberculosis (TB) co-ordinating team on health service performance for suspected TB patients in a district hospital in northeastern Thailand. Design/methodology/approach - A comparison study of pre- and post-evaluations of TB system improvement was conducted in a district hospital in northeastern Thailand between October 2016 and June 2017. Data collection reviewed the record of suspected TB cases reported in the district hospital in the past nine months as a base line for describing the health service performance in term of received investigation for TB diagnosis. Participants from a TB clinic, district health office and health center set up a TB co-ordinating team to explore situations and systematic gaps. The TB co-ordinating team gave recommendations of health service performance for suspected TB patients over a nine-month period. Records of suspected TB cases health service performance were collected nine months after intervention. Data analysis by descriptive statistics and to test the effect of intervention was performed.

Findings - The records from 324 and 379 suspected TB cases reported in the hospital from the 9 months preceding and 9 months, respectively, after intervention were reviewed. A TB co-ordinating team was set up to improve the system and health service performance in terms of investigation for TB diagnosis. The results revealed that health service performance in terms of complete microscopy and investigation in both chest radiography and microscopy increased after intervention. When comparing between pre- and post-intervention, suspected cases received both chest radiography and microscopy in 176 cases and 283 cases, respectively ( $p$-value $=0.001$ ). There were 27 cases diagnosed for smear positive TB in pre-intervention and 51 cases diagnosed in post-intervention $(p$-value $=0.011)$. There were 21 cases pre- and 36 cases post-intervention that had referral documents from health center with no statistically significant difference.

Originality/value - The TB co-ordinating team had the role to improve health service performance for suspected TB cases to enroll in investigation process for increase TB diagnosis in district hospital.
\end{abstract}

Keywords Health service performance, Suspected tuberculosis patient, TB co-ordinating team

Paper type Short report

\section{Introduction}

Tuberculosis (TB) remains a major global health problem as a cause of death from an infectious disease worldwide. In 2012, an estimated 8.6 million people developed TB and 1.3 millon died. Nearly 20 years after the World Health Organization (WHO) declaration of TB as a global public

(c) Sasithorn Tangsawad and Surasak Taneepanichskul. Published in the Journal of Health Research. Published by Emerald Publishing Limited. This article is published under the Creative Commons Attribution (CC BY 4.0) licence. Anyone may reproduce, distribute, translate and create derivative works of this article (for both commercial \& non-commercial purposes), subject to full attribution to the original publication and authors. The full terms of this licence may be seen at http://creativecommons. org/licences/by/4.0/legalcode

The authors appreciate all the staff of Selapoom district hospital and the district TB co-ordinating team for collaboration and assistance in the study.

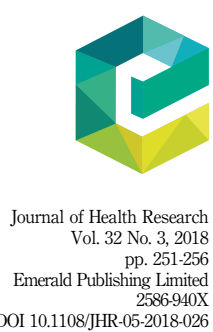


JHR

32,3

252

health emergency, major progress has been made within the context of the 2015 Millennium Development Goals[1]. Thailand is one of the 22 ranked TB high burden countries in the world from The WHO Global Tuberculosis Report 2012. Within its population of 67 million, Thailand had about 86,000 TB incident cases and 110,000 TB prevalent cases, and a treatment success rate for TB of 85 percent in 2010. Among these, 44,000 cases were smear positive which are contagious and important in the role of TB control programs. There are approximately 13,000 deaths from TB each year. Thailand has full DOTS coverage, and TB services are available in many hospitals. Thailand has a policy for expanding and enhancing TB diagnosis and care at all levels in district settings. The community and subdistrict level play roles in DOTS and home visits. The case notification rate of new smear positive TB in Thailand since 2010-2014 was under the estimate rate of WHO (the estimate of case notification rate was 66 per 100,000 population). The gap between case notifications and the real incidents cases was due to underreporting of diagnosed $\mathrm{TB}$ and under diagnosis due to failure to detect cases in health care facilities[2]. The systems for TB control in tracing and referral system now are different in each district, and this affects the case detection[3]. The 5th Joint International Monitoring Mission took place in August 2013, bringing together external experts and national staff to review the performance of TB care and prevention activities in different settings. The review team prioritized their main concerns in low case notifications in report system of TB cases in the national underreporting is significant and below estimated rates[4] .In the current systems, there are no specific roles of tracing of follow-up for suspected TB cases for health personnel in the district health office or at the health center depending on the context in each district. In this research, to explore the situation of health service performance of suspected TB cases in community or district hospital, especially in a low prevalence district, it was expected that district TB co-ordinating team should play a role to improve health service performance on TB diagnosis. The objective of this research was to study the efficacy of the district TB co-ordinating team on health service performance for suspected pulmonary tuberculosis patients (PTB) in a district hospital.

\section{Ethical consideration}

This study followed the details of the approval of the Ethical Committee of Chulalongkorn University. The intervention was done following the process of ethical issues with the purpose of providing benefit to the participants and keeping confidentiality (COA NO. 158/2016).

\section{Methodology}

The comparison study of evaluations pre- and post-intervention of TB system strengthening was conducted in northeastern part of Thailand. The district hospital was selected based on the geographical area by the criteria of being located in a low prevalence province in the region and also having a low prevalence in TB confirmed cases. All records of suspected TB cases reported in the hospital in the past nine months were reviewed in term of health service performance for suspected TB cases, chest radiography and complete microscopy. The 18 team participants were all health personnel who are responsible for TB health service including physicians, nurses, medical technologists from the TB clinic in the hospital, and health personnel from the district health office and health centers formed the TB co-ordinating team and set up the role of each participant to improve health service performance for suspected TB cases. The intervention (set-up role and function of the district TB co-ordinating team) was implemented. After nine months of following the assigned roles, all records of suspected TB cases reported in the hospital in the past nine months were reviewed in the same variables of the previous nine months before intervention. Data analysis by descriptive in pre- and post-intervention by comparing outcomes in the nine months intervention period and the nine months base line by the $\chi^{2}$-test. The main outcome of the study was confirmed pulmonary TB (smear positive) cases. 
Research tools

The case record form of suspected cases for data collecting include age, sex, occupation and in terms of health services for suspected TB cases, microscopy and chest radiograph (CXR), and referral document.

\section{Intervention}

The first day of the workshop schedule is giving TB knowledge for all participants including discussions updating TB status, TB signs and symptoms, TB transmission, diagnosis and treatment. The participants consist of all TB clinic staffs in the hospital including two doctors, three nurses, one hospital TB co-ordinator, one medical technologist from the laboratory room, one health personnel from the district health office and ten from health centers who responsible for TB health service in the district.

The second day of workshop schedule deals with strengthening the system by defining the current system gap. Situations of TB in the district will be discussed with all participants and finding the gap of health service performance on suspected TB cases. The details of the existing referral system will be discussed and together set up the roles for the working process. The output of the workshop was the formation of a district TB co-ordinating team and flow of TB health service system, together with a defined role and function of each participant.

\section{Results}

In pre-intervention, 324 records of suspected PTB cases reported in the hospital in the preceding 9 months were reviewed in term of health service performance for suspected TB cases. The analysis of suspected PTB cases visiting the hospital to be diagnosed found that the mean patient age was 57.75 years; most were more than 60 years old (48.77 percent). In 210 cases (64.81 percent), the patients were agriculturists. Among the 324 cases, 25 pulmonary TB smear positive patients were registered for treatment at the hospital, and two cases were referred to another hospital for treatment. Post-intervention, the 379 records of suspected TB cases reported in the hospital after the nine-month intervention period were reviewed as in the pre-intervention group. The mean age was 58.31 years; most were more than 60 years old (50.66 percent). In 261 cases (68.87 percent), the patients were agriculturists. Among all 379 cases, 48 pulmonary TB smear positive cases were registered for treatment at the hospital and 3 cases were referred to another hospital for treatment (Table I).

According to the analysis by the $\chi^{2}$-test in terms of the outcome of the study, suspected TB cases received a schedule for both CXR and completed microscopy (three times for sputum microscopy), which, compared in pre- and post-intervention, were 176 and 283 cases, respectively. The difference was found to be statistically significant $(\phi$-value $=0.001)$. For TB diagnosis, the 27 cases diagnosed for smear positive TB in pre-intervention and 51 cases diagnosed in post-intervention are statistically significant $(p$-value $=0.011)$. For the referral system, there were 21 and 36 cases in pre- and post-intervention, respectively, arrived at hospital with referral document, but these numbers were found to be not statistically significant (Table II).

In order to build a district TB co-ordinating team, 14 participants including physicians, nurses, medical technologists from the hospital, health personnel from the district health office and health center set up a workshop to improve the health service performance for suspected TB patients. The analysis and defining systematic gaps of health service performance on suspected TB cases in the existing situation was done on the second day of the intervention process. The details of the existing situation of health service performance for suspected TB patients in the community hospital were as follows:

(1) the participants involved in TB health service worked in their role and function in their setting, but they were not clear in terms of their role among the district level and health center level; and
District TB co-ordinating team 


\begin{tabular}{|c|c|c|c|c|c|c|c|}
\hline & Pre-in & tion & Post-in & tition & & & \\
\hline & $n=324$ & $(\%)$ & $n=379$ & $(\%)$ & $\chi^{2}$ & $\mathrm{df}$ & $p$-value \\
\hline $\begin{array}{l}\text { Age (years) } \\
15-20 \\
21-30 \\
31-40 \\
41-50 \\
51-60 \\
>60\end{array}$ & $\begin{array}{c}8 \\
21 \\
25 \\
54 \\
58 \\
158 \\
\bar{X}=57.75 \\
\text { Min }=15,1\end{array}$ & $\begin{array}{r}2.47 \\
6.48 \\
7.72 \\
16.67 \\
17.90 \\
48.77 \\
17.287) \\
90\end{array}$ & $\begin{array}{c}8 \\
19 \\
38 \\
41 \\
81 \\
192 \\
\bar{X}=58.31 \\
\text { Min }=16\end{array}$ & $\begin{aligned} & 2.11 \\
& 5.01 \\
& 10.03 \\
& 10.82 \\
& 21.37 \\
& 50.66 \\
&=16.43) \\
& 90\end{aligned}$ & 7.84 & 5 & 0.165 \\
\hline $\begin{array}{l}\text { Occupation } \\
\text { Agriculturist } \\
\text { Employer } \\
\text { Government officer } \\
\text { Commercial } \\
\text { Other }\end{array}$ & $\begin{array}{r}210 \\
60 \\
5 \\
2 \\
47\end{array}$ & $\begin{array}{r}64.81 \\
18.52 \\
1.54 \\
0.62 \\
14.51\end{array}$ & $\begin{array}{r}261 \\
46 \\
9 \\
2 \\
61\end{array}$ & $\begin{array}{r}68.87 \\
12.14 \\
2.37 \\
0.53 \\
16.09\end{array}$ & 6.064 & 4 & 0.194 \\
\hline $\begin{array}{l}\text { Registered for TB treatn } \\
\text { Hospital } \\
\text { Refer to other hospital }\end{array}$ & $\begin{array}{r}\text { ent at } \\
25 \\
2\end{array}$ & $\begin{array}{r}92.59 \\
7.41\end{array}$ & $\begin{array}{r}48 \\
3\end{array}$ & $\begin{array}{r}94.11 \\
5.89\end{array}$ & 0.037 & 1 & $0.596^{\mathrm{a}}$ \\
\hline
\end{tabular}

Table I.

Characteristics of suspected TB cases and health service performance in district hospital

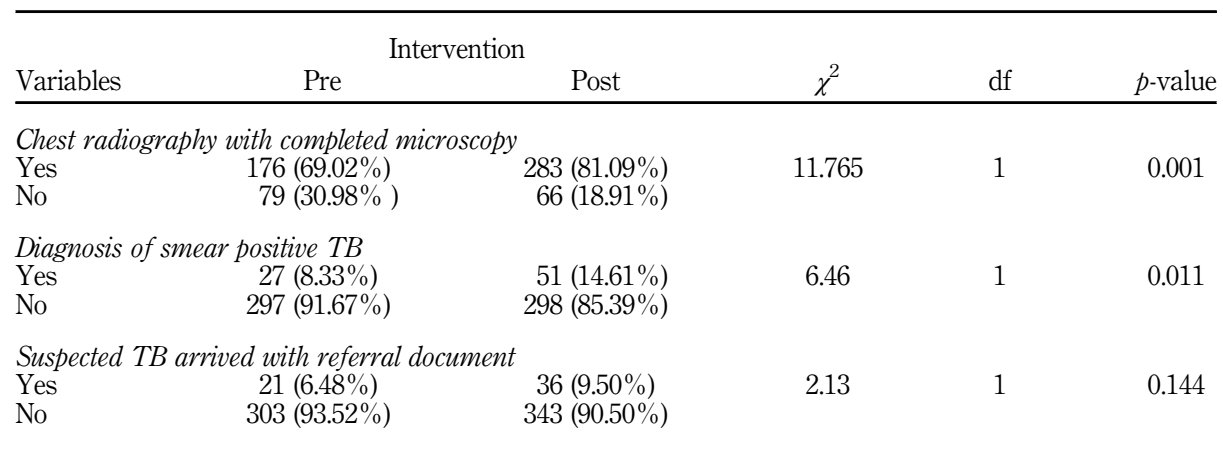

(2) the hospital had the records for TB health service but there was no system to evaluate the information about suspected TB cases investigated for TB diagnosis at the hospital.

To improve health service performance in both function and information, recommendations were suggested by the participants for a system to improve health service performance as follows:

(1) Work structure: set up district TB co-ordinating team including physician, nurses, medical technologist, district health personnel, health center personnel. The district TB co-ordinating team TB is responsible for collaborating and monitoring the work process together.

(2) Work process: by specifying the process when suspected TB cases have to be referred from the health center to the hospital. The health center screens the suspected cases and then refers to the hospital by indication with the referral document:

- The hospital sets up a hospital TB co-ordinator: the hospital TB co-ordinator has the role to follow up with patients to get complete investigation including chest radiography and microscopic examination by collaborating and sharing 
information with the outpatient department, patient department and medical technologist. The hospital TB co-ordinator also will co-ordinate with the district health office to follow up suspected cases by the health center team.

- The district health officer has to monitor the health center for the follow-up process of the suspected $\mathrm{TB}$ cases to get complete investigation and treatment.

- Monitoring and evaluation system: the district TB co-ordinating team will meet regularly to share information and solve problems.

\section{Discussion}

Although all hospitals in Thailand can diagnose TB by microscopy and chest radiography, suspected TB cases need more attention in order to complete three microscopy examinations and receive follow-up scheduled exams for complete investigation by both chest radiography and microscopy. The results found statistically significant $(p$-value $=0.001)$ differences in incidence of chest radiography with completed microscopy in pre-intervention and post-intervention after diagnosis of smear positive TB ( $p$-value $=0.011$ ). The number of smear positive cases also increased from 27 to 51 cases. When compared with the study at primary health care clinics in South Africa by reviewing $62 \mathrm{~TB}$ patients, it was found that 41.9 percent were diagnosed using microscopy while chest radiography was done in 37.1 percent. The method used depends on TB symptoms and screening practice at health facilities and turnaround time for delivery on results[5]. In this study, we found that a district TB co-ordinating team plays a role in improving the health service performance of $\mathrm{TB}$ for increasing the rate of investigation and confirmed cases. In regards to the referral system, we found no statistical difference in terms of suspected TB arrived with a referral document from health center. To increase the referral rate of suspected TB cases to the hospital, community and village health volunteers may take part. In Thailand, village health volunteers and health personnel in health centers also have the role in the community to screen for suspected TB cases. The study of village health volunteer participation in TB control in southern Thailand revealed that village health volunteers as well as the health workers in the health center played a role in TB detection case by screening[6, 7]. A cross-sectional descriptive research conducted to study the performance of village health volunteers on TB prevention found that 56.51 percent of village health volunteers had a high performance level for TB prevention in terms of knowledge. Village health volunteers have the role of providing health education/health information, co-ordinating with health centers, launching an active case finding program, reporting the number of TB suspected cases, sending sputum for microscopy and advising TB suspected cases to visit a hospital. The study in China found that cooperation between different public and private health institutes involved in TB control has proven to enhance TB control in referral, tracing and arrival rates after the implementation of the cooperation mechanism[8]. Active case finding for TB has been recognized as important to increase the cases being missed by the health system[9]. Systematic TB screening may help detect more cases by defining risk groups with screening and diagnostic algorithm options[10]. Passive case finding using sputum smear microscopy is not enough. Early diagnosis and treatment of smear positive TB in persons with chronic cough is of highest priority for reducing TB transmission[11]. Different populations may be screened using a variety of algorithms include symptoms, CXR and sputum for smear microscopy[12]. Direct nucleic acid amplification tests are playing an increasingly important role in the diagnosis of TB[13]. Thailand has been estimated to have a TB burden of 171 per 100,000 population, a higher rate than previously reported[14]. Thailand is now currently working with international partners such as the US Center for Disease Control to assess the impact of new diagnostic techniques and approaches to prevent the spread of TB in health care settings[15]. 
According to the district TB co-ordinating team that was set up for improving the health service for suspected TB cases, the systems of referral, follow-up and monitoring were taken into account for consideration. The hospital TB co-ordinator played the role in collaboration within each department in the hospital and district health office for co-ordinating with the health center for the follow-up of appointed cases to investigation, especially microscopic examination, by receiving the schedule from the follow-up at hospital until the completion of microscopy.

\section{References}

1. World Health Organization [WHO]. Global tuberculosis report 2013; 2013 [cited 2014 Feb 21]. Available from: http://who.int/tb/publication/global_report/en

2. World Health Organization [WHO]. Global tuberculosis report 2014; 2014 [cited 2014 Jul 25]. Available from: www.who.int/tb/people_and_communities/en/

3. Bureau of Tuberculosis Control. Department of Disease Control. National Tuberculosis Prevalence Survey in Thailand 2012-2013. Bureau of Tuberculosis Control, Nonthaburi (in Thai); 2013.

4. Ministry of Public Health. National strategic plan for tuberculosis prevention, treatment and care 2016-2020. Nonthaburi: Ministry of Public Health; 2016.

5. Musoke J, Michel LA. Characteristics of tuberculosis patients and the evaluation of compliance to the national TB management guidelines at clinics in a rural community from Mpumalunga province. S Afr J Infect Dis. 2016 May; 31(4): 135-37.

6. Phomborphub B, Pungrassami P, Boonkitjaroen T. Village health volunteer participation in tuberculosis control in Southern Thailand. Southeast Asian J Trop Med Public Health. 2008 May; 39(3): 542-48.

7. Rakwong N, Sillabutra J, Keiwkarnka B. Performance of village health volunteers on tuberculosis prevention in Mahachanachai district, Yasothon province, Thailand. J Pub Health Dev. 2010 Sep; 8(3): 253-64.

8. Zhang T, Guo L, Zhang S. Improving detection and notification of tuberculosis cases in students in Shaanxi province, China: an intervention study. BMC Public Health. 2011 Mar; 11: 147. Available from: https://oi.org/10.1186/1471-2458-11-147

9. Ho J, Fox JG, Marais JB. Passive case finding for tuberculosis is not enough. Int J Mycobacteriol. 2016 Dec; 5(4): 374-78.

10. Uplekar M, Creswell J, Ottmani SE, Weil D, Sahu S, Lonnroth K. Programmatic approached to screening for active tuberculosis. Int J Tuberc Lung Dis. 2013 Oct; 17(10): 1248-56.

11. Lönnroth K, Corbett E, Golub J, Godfrey-Faussett P, Uplekar M, Weil D, Raviglione, M. Systematic screening for active tuberculosis: rational, definitions and key considerations. Int J Tuberc Lung Dis; 2013; 17(3): 289-98.

12. Kranzer K, Holmes A, Tomlin K, Golub JE, Shapiro AE, Schaap A, et al. The benefit to communities and individuals of screening for active tuberculosis disease: a systematic review. Int J Tuberc Lung Dis. 2013 Apr; 17(4): 432-46.

13. Jeans C, Gray OJ. Diagnosis tuberculosis in the 21st century-dawn of genomics revolution? Int J Mycobacteriol. 2016 Dec; 5(4): 384-391.

14. World Health Organization [WHO]. Global tuberculosis report 2015; 2015 [cited 2018 Jan 2]. Available from: www.who.int/tb/publications/global_report/gtbr15_annex02.pdf

15. Centers for Disease Control and Prevention $[C D C]$ in Thailand. Centers for disease control and prevention: fact sheet; 2017 [cited 2018 Jan 2]. Available from: www.cdc.gov/globalhealth/ countries/Thailand/pdf/Thailand_Factsheet.pdf

\section{Corresponding author}

Surasak Taneepanichskul can be contacted at: surasakta@yahoo.com

For instructions on how to order reprints of this article, please visit our website:

www.emeraldgrouppublishing.com/licensing/reprints.htm

Or contact us for further details: permissions@emeraldinsight.com 